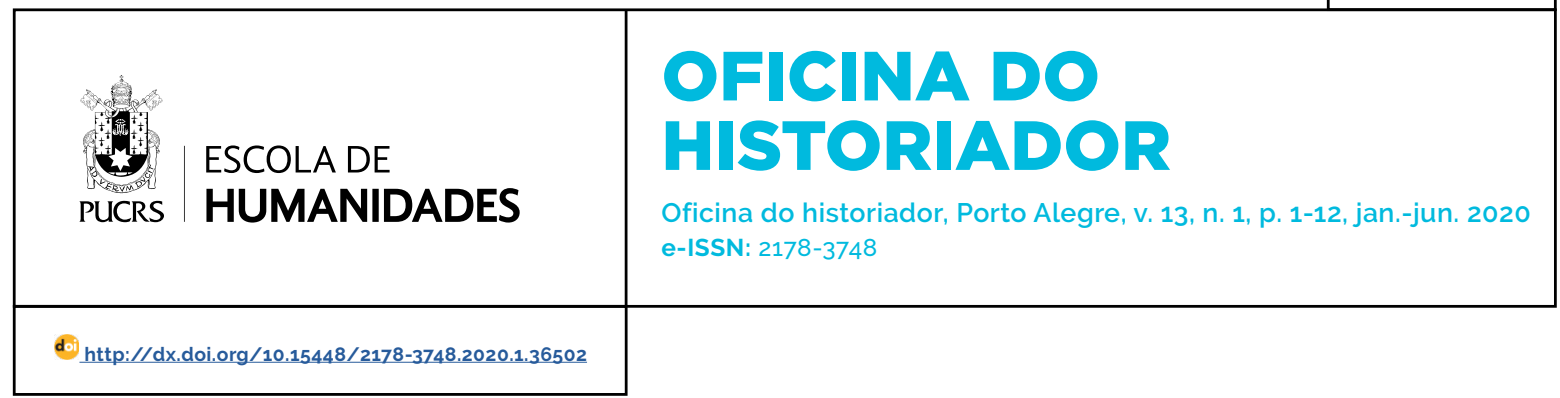

SEÇÃO: DOSSIÊ

\title{
Estudos de cultura material: sobre coisas e substâncias na Arqueologia
}

\author{
Material culture studies: on things and stuff in Archaeology
}

\author{
Klaus Hilbert ${ }^{1}$ \\ orcid.org/0000-0002-7672-6540 \\ hilbert@pucrs.br
}

Recebido em: 21 nov. 2019

Aprovado em: 29 jan. 2020

Publicado em: 14 jun. 2020.

\section{(c) (i)}

Artigo está licenciado sob forma de uma licença Creative Commons Atribuição 4.0 Internacional.
Resumo: Este ensaio espera tratar das qualidades da cultura material e das substâncias, as comunicativas e as expressivas, independentemente de qualquer limite cronológico e através de um diálogo interdisciplinar com arqueólogos, antropólogos, historiadores, sociólogos, economistas, psicólogos e filósofos. Minha expectativa para este texto é de incorporar ao estudo de cultura material as interferências das coisas, bem como das substâncias, no registro e nas práticas arqueológicas. Alguns estudos de cultura material valorizam o significado das coisas e das substâncias e partem da ideia de que esses podem ser percebidos e vistos como signos que auxiliam seus donos e usuários nos processos comunicativos, e na formação de identidades. Acredito que perceber esses processos como uma rede dinâmica de inter-relações ajudará a estabelecer conexões fenomenológicas precisas e participativas com os demais membros da sociedade, além de entender melhor as relações simétricas entre pessoas, coisas e substâncias. Palavras-chave: Arqueologia Fenomenológica. Arqueologia Semiótica. Cultura Material. Substâncias.

Abstract: This essay hopes to address the communicative and expressive qualities of material culture and of stuff, regardless of any chronological limit and through an interdisciplinary dialogue with archaeologists, anthropologists, historians, sociologists, economists, psychologists and philosophers. My expectancy to this text is to incorporate into the study of material culture the interference of things as well as stuff into the record and archaeological practices. Recent studies of material culture emphasizes the meaning of things as well as stuff and start from the idea that they can be perceived and seen as signs that help their owners and users in their communicative processes, and in the formation of identities. I believe that perceiving these processes as a dynamic network of interrelations will help establish accurate and participatory phenomenological connections with other members of society, and better understand the symmetrical relationships between people, things, and stuff.

Keywords: Phenomenological Archaeology. Semiotic Archaeology. Material Culture. Stuff.

\section{Introdução}

Este ensaio justifica-se pela necessidade de pensar em novas formas de teorizar e praticar Arqueologia. Como disciplina e profissão, a Arqueologia brasileira passou nos últimos trinta anos por mudanças significativas (LIMA, 2002). Em comparação com uma Arqueologia tradicional homogeneizada, na atualidade, a Arqueologia está caracterizada por uma ampla variedade de perspectivas, linhas de ações e de diversificação. Enquanto alguns autores, como Bjørnar Olsen (2003), argumentam que essa diversificação 
simplesmente existe porque um fragmento é mais resistente às criticas do que uma abordagem holística, outros percebem essa tendência positivamente como uma conquista do pluralismo (HODDER, 1983). Na Arqueologia tradicional, até o final da década de 1980, profissionais, como, por exemplo, Lewis Binford (1989, p. 3) ainda afirmavam, categoricamente, que: "Não estudamos comportamento humano [...] não estudamos códigos simbólicos, não estudamos sistemas sociais, não estudamos culturas antigas, não estudamos antigos assentamentos,., nem estudamos o passado. Estudamos artefatos". (BINFORD, 1989, p. 3, tradução nossa). ${ }^{2}$

Essa definição das ações dos arqueólogos, que percebe a cultura material como algo estático e distante da vontade do arqueólogo de interferir com coisas e substâncias, limita sua área de atuação. Ela desconsidera a grande variedade de ações e de relações que a cultura material tem sobre a vida das pessoas, pois arqueólogos fazem muito mais que apenas estudar artefatos. Arqueólogos lidam também com substâncias, com artefatos, separam coisas e objetos das substâncias, selecionam coisas e artefatos da cultura material encontrada em um sítio arqueológico, transformam cultura material em letras, em linguagem, emendam palavras, criam textos, e transformam textos em narrativas. Arqueólogos são mutáveis e hibridos e, para falar melhor sobre algo tão difícil quanto as coisas arqueológicas, bem como todos nós, inventam linguagens, criam metáforas, nomeiam coisas e substâncias, contam histórias, cultivam lembranças, apagam memórias, além de escrever sobre outros arqueólogos. A lida com as coisas arqueológicas está relacionada com a história, com as pessoas, com suas próprias memórias e com as dos outros. Arqueologia é uma maneira de tornar a história local relevante para grupos excluídos da história oficial (SHACKEL, 2004, p. 2).

A forma de análise de cultura material arqueológica está vinculada aos motivos que me levaram a desenvolver este texto que, por sua vez, estão diretamente relacionados à minha atuação como docente. Em decorrência da exigência cada vez maior por parte dos mestrandos e doutorandos, acerca de conhecimento teórico e metodológico atualizado, considerei oportuno investir na minha capacitação intelectual e pedagógica, já que, as pesquisas arqueológicas desenvolvidas por mim e por muitos outros colegas no Brasil, necessitam de objetivos renovados, precisam de preocupações científicas relacionadas mais com perguntas e dúvidas que possam instigar respostas que não estejam apenas na zona das certezas e respostas $a$ priori corretas. Neste percurso, na busca de novos horizontes intelectuais, apresento alguns exemplos e potencialidades dos estudos de cultura material na Arqueologia que considero, momentaneamente, interessante. Tania Andrade Lima (2011) publicou um ensaio sobre a dimensão concreta das relações sociais da cultura material que recomendo aos leitores interessados no estudo da cultura material.

Entretanto, essa minha proposta sobre coisas, substâncias e pessoas é, fundamentalmente, um experimento literário que privilegia o diálogo entre a Filosofia Fenomenológica, a Semiótica, a História e a Arqueologia. Um diálogo que, a meu ver, tenta formular propostas novas e instigantes. A metodologia de trabalho está relacionada com as abordagens semióticas, fenomenológicas e arqueológicas apresentadas na sequência.

\section{Sobre cultura material}

Entendemos por cultura material a soma de todos os objetos, materiais, substâncias, coisas, artefatos, mercadorias, bens manipulados e materializados em uma sociedade ou que possuem significado. Não se trata, por nada, em medir seu valor ou peso de significado, mas seu envolvimento no mundo vivido das pessoas. Cultura material é cultura transformada em matéria, é cultura materializada (KNAPPETT, 2014). Combina o visivel com o invisivel, sem privilegiar uma forma sobre a outra. Cultura é

\footnotetext{
2 Do original: We do not study human behavior [...]. we do not study symbolic codes, we do not study social systems, we do not study ancient cultures, we do not study ancient settlements, nor do we study the past. We study artifacts.
} 
definida como um padrão na mente das pessoas, interno, invisivel, mutável. O material, por outro lado, é sólido e se projeta para fora, se transforma em cultura, é transformado por cultura, segundo o ato de sabedoria que também atuará no mundo (GLASSIE, 1999, p. 7). O estudo da cultura material emprega coisas e substâncias para se aproximar dos pensamentos e das ações das pessoas. Não queremos colocar a ideia nobre sobre a matéria bruta, dualidade praticada no mundo ocidental desde os tempos de Platão, ou fortalecer a dicotomia entre o material e o imaterial, é o mundo intermediário que me interessa (CASSIRER, 1923). Karl Kramer (1995) sugere o conceito da "Dingbedeutsamkeit" (Significado da coisa) como uma forma de conectar o espiritual com o material nos estudos de cultura material. A percepção do mundo material, a agência das coisas e das substâncias do nosso dia a dia e de seus significados, temáticas, da forma como são tratados atualmente, também têm poucas relações com os antigos estudos de cultura material praticados por etnólogos do século XIX.

A preocupação científica com essas temáticas provocou uma verdadeira onda nos estudos de cultura material, perceptivel nas pesquisas da Arqueologia, da Etnologia, dos Estudos Culturais, da Sociologia, da História, da História da Arte e dos Estudos da Economia e do Folclore. A cultura material, conforme os novos paradigmas, não considera apenas o objeto na sua forma material, mas também seus contextos. Essas abordagens contextuais se revelaram como as mais importantes chaves para os estudos do cotidiano (APPADURAI, 1986; LUBAR; KINGERY, 1993; REDE, 1996; 2001; BUCHLI, 2002; WOODWARD, 2007; HILBERT; MARQUES, 2009; HILBERT, 2019).

Cultura material é parte fundamental do mundo vivido da sociedade. Ela assume um papel importante na formação da identidade das pessoas, bem como faz parte da formação da sociedade como um todo. Uma possivel área de estudos de cultura material trata da materialidade das coisas, das substâncias e das suas percepções. Nesta área, esses podem estar relacionados com a memória e a lembrança, com a biografia das coisas e das substâncias. Outra área abrange a manipulação das coisas e das substâncias. Temáticas como, por exemplo, os modos de vida e consumo, tratados por Georg Simmel (1900) e Thorstein Veblen (1987) ou através de abordagens mais recentes que envolvem o meio social, a crítica ao consumismo, mudanças nos padrões de consumo, mercadorias e bens, as formas da obtenção, apropriação, a troca, a dádiva de materialidades e das substâncias, ou a lida com as coisas do dia a dia nas unidades domésticas.

Henry Glassie (1999), que já no final da década de 1960 junto com James Deetz (1996) refletiu sobre o significado dos pequenos objetos esquecidos, registrou histórias interessantes baseadas em coisas descartadas e esquecidas. Christoph Eykman, (1999) encontra essas pequenas coisas esquecidas na literatura de Rilke, Melville, Neruda, Brecht, Handke, Flusser, Caillois e outros. Glassie (1999, p. 6) afirma que às vezes dominamos os objetos. Nós analisamos, numeramos e classificamos as evidências arqueológicas. Às vezes, somos dominados pelos objetos. Eles nos seduzem e despertam desejos. Os resultados desses diálogos conflitantes são histórias. Essas histórias iniciam na vontade do historiador, do arqueólogo que, em um ato de coragem, ignora a maioria das pessoas e dos eventos, seleciona uma pequena fração dos fatos, arrumando-os de forma artística, para falar sobre a condição humana. Henry Glassie compreende os historiadores, e todos os outros que "deal" (negociam) com a cultura material, como alguém que compõe histórias que funcionam dentro de um roteiro social, agrupando pessoas e refinando suas relações pessoais na base de uma cosmologia compartilhada.

\section{Sobre substâncias como cultura material}

Entende-se por substâncias - "Stoffe" em alemão ou "Stuffs" em inglês - que elas ocorrem, elas aparecem, se revelam. As substâncias são parceláveis, são espécies naturais, elas têm tendências, qualidades, são materiais. Objetos e coisas, entretanto, têm lados, se escondem, aparecem, têm tendências, têm história, são 
substanciais (SOENTGEN, 1996, 2008, BARNETT, 2004; BROACKES, 2004).

Registros etnográficos e arqueológicos contêm um rico acervo de informações sugerindo que a compreensão do mundo das substâncias é culturalmente diversificada (TAÇON, 1991; HOSLER, 1995; JONES; MacGREGOR, 2002; SAUNDERS, 2002). Para Hahn e Soentgen (2010) substâncias são, por exemplo: poeira, água, fumaça, solo, pus, areia, mel, colostro, látex, betume, farinhas, argila, massa corrida, lama, gosma, chorume, mingau, catarro, pasta de dente, fezes, creme, vaselina, cera, piche, saliva, açúcar, sal, talco etc. Mas nem todas as pessoas e nem todas as sociedades percebem substâncias (Stoffe), simplesmente como matériaprima ou como commodities que podem ser explorados com finalidades econômicas, como elementos passivos, sem tendências próprias de se organizarem. Substâncias têm significados simbólicos, retêm poderes mágicos, são atuantes, não apenas em seus aspectos econômicos mas, profundamente envolvidos nos aspectos sociais, cosmológicos, místicos, espirituais e filosóficos (HOLBRAAD, 2007).

Outra caracteristica de substância sobre a qual pretendo refletir brevemente é que substâncias têm tendências ou inclinações. Como vimos anteriormente, uma substância não é apenas matéria-prima que ganha valor quando é transformada em artefato, consequentemente moldável e controlável pelo sujeito que impõe seu domínio sobre a matéria. Substâncias não são apenas porções vazias, elas têm caracteristicas ativas e produtivas. A umidade, por exemplo, tem a tendência de se espalhar, de se misturar, enquanto a poeira tem a inclinação de voar, entrar nos olhos ou descansar sobre os livros na estante. Não se trata aqui, em absoluto, de um antropomorfismo. Não estou sugerindo que substâncias têm personalidades, vícios ou vontades próprias. Mas não podemos negar que substâncias, e, naturalmente, as coisas, têm poderes sobre nós, e que também tiveram sobre as pessoas no passado. Antropólogos culturais e sociais mostraram a influência que as coisas exercem sobre as pessoas, em supermercados, "shoppingcenters", nas canoas dos povos polinésios, nas igrejas etc. (McCRACKEN, 2003; GELL, 1998).

Enquanto aspectos simbólicos sobre a interação entre pessoas, plantas, animais, paisagens e outros elementos do mundo natural são discutidos, muito pouco tem-se publicado na Arqueologia sobre substâncias (BOIVIN; OWOC, 2004). Isso surpreende, já que arqueólogos, em suas pesquisas, estão diretamente envolvidos por e com substâncias em forma de sedimentos, argilas, poeiras e terras orgânicas, muitas vezes, estratificadas. Os arqueólogos, em sua grande maioria, percebem substâncias apenas como uma categoria geoarqueológica em forma de sedimento e como contentores dos achados arqueológicos, dos objetos desejados e não como uma cultura material com caracteristicas próprias como afirma, por exemplo Bruno LATOUR (1999, p. 39).

Umautor emblemático para essa abordagem que previliegia as coisas arqueológicas sobre as substâncias é André Leroi-Gourhan. Em seus estudos valiosos sobre L'homme et la matière (1943), ele apresenta uma grande quantidade de técnicas, aplicadas pelas sociedades prémodernas, através das quais artefatos podem ser produzidos e utilizados. No entanto, quero chamar atenção para uma lacuna considerável nos seus estudos, nos quais ele se dedicou, quase exclusivamente, às tecnologias "duras" e ativas e aos artefatos que podem ser diretamente produzidos e usados. Mas, além dessas práticas, existem outras, onde o produto final desejado não pode ser produzido diretamente, que envolvem substâncias e coisas e suas transformações através de um processo predominantemente passivo.

A ação ativa nesse processo de transformação das substâncias e dos artefatos limita-se em criar as condições básicas para que, no final do processo, ela aconteça sozinha. O controle da temperatura, a oxigenação e as condições de umidade são comandados externamente, substâncias e coisas são acrescentadas, misturadas e logo depois a transformação se desenvolve internamente e por força própria. Essas tecnologias "moles" ocorrem, por exemplo, 
na preparação dos alimentos e das bebidas fermentadas, na preparação da argila para a fabricação da cerâmica, no tratamento prévio ao lascamento do material lítico, na vulcanização da borracha, na produção de curare, do fumo, da coca, da farinha de mandioca, em uma infinidade de coisas em que a materialidade é perpassada pelas substâncias (SOENTGEN; HILBERT, 2016).

A falta da preocupação dos arqueólogos com substâncias pode estar relacionada com os paradigmas teóricos, que tratam, predominantemente, de explicar artefatos e de descrever a maneira como foram produzidos (BOEDA, 1997; FOGAÇA, 2001; HOELTZ, 2007). Como as substâncias são frequentemente vistas apenas como fontes de matériasprimas, passivamente aguardando para serem exploradas, sugerimos uma abertura do leque das possibilidades objetivas da pesquisa arqueológica. As substâncias, mesmo passando por transformações, quando da exploração enquanto matérias-primas, seguem sendo substâncias, em sua resistividade, reduzidas ou agregadas a outras substâncias na interação no espaço e ao longo do tempo.

Substâncias também interferem diretamente em nossas vidas e devem ser tratadas, junto com as coisas, os artefatos, as narrativas, os textos e as imagens como parte da cultura material. Substâncias criam cronologias, criam pátinas que fazem as coisas parecerem mais ou menos antigas. As pátinas são signos indiciais dos parâmetros de tempo. Indicam o tempo, faz o tempo arqueológico e são, por sua vez, sujeitas às mudanças do tempo. O significado das substâncias, tal qual o da cultura material, está sujeito às transformações culturais e sociais. Pesquisas arqueológicas, sem considerar de forma simétrica as substâncias, cultura material e pessoas, são pesquisas apenas parciais.

\section{Sobre as palavras, as coisas e as substâncias}

Alguns estudos de cultura material valorizam o significado das coisas e partem da ideia de que essas coisas podem ser vistas como signos que auxiliam seus donos e usuários na comunicação entre as pessoas, além de expressar suas identidades. Essas duas qualidades da cultura material, a comunicativa e a expressiva, representam dois conceitos distintos, e ao mesmo tempo relacionados. Os trabalhos mais socioantropológicos de Mary Douglas e Baron Isherwood sobre o Mundo dos Bens (2004) ou de Pierre Bourdieu, Outline of a theory of practice (1977) enfatizam o caráter comunicativo e estrutural dos objetos. O outro conceito, mais situado na área da psicologia cultural, destaca os atributos expressivos e de identidades na cultura material. Esses aspectos foram valorizados, por exemplo, nas investigações de Mihaly Csikszentmihalyi e Eugène Rochberg-Halton em The Meaning of Things: Domestic Synbols and the Self (1999), ou por Helga Dittmar, em The Social Psychology of Material Possessions (1992).

Decisivo para esses conceitos comunicativos e expressivos da cultura material é sua contextualização. Objetos contextualizados podem ser percebidos em analogia a textos interligados. Coisas, vistas como signos, formam seus significados muito menos por suas qualidades materiais e individuais, do que pelos contextos, pelas situações sociais nas quais estão inseridos e nas quais foram usados e criados (MILLER, 1987, p. 11). Diante desse pano de fundo, a sociedade como um todo forma uma relação de significados e de representações em que a cultura material pode ser interpretada através dos conceitos teóricos da semiótica (DEETZ, 1996; LEROI-GOURHAN, 1943; HAHN, 2003, 2005; PREUCEL, 2006; HILBERT, 2009, 2010).

Para Ferdinand de Saussure (1989) existem dois principios básicos em torno do qual a linguística estrutural está organizada. Primeiro: não existem termos positivos, apenas referências. Esse caráter referencial e diferencial das identidades linguísticas significa que a lingua constitui um sistema em que nenhum elemento pode ser definido independentemente do outro. Signos adquirem seus significados por serem diferentes dos outros signos. Segundo: língua é forma. Cada elemento do sistema linguístico é definido, 
exclusivamente, através das regras de combinação e de substituição com outros elementos.

Umberto Eco (1991, p. 4) define semiótica, em princípio, como a "disciplina que estuda tudo quanto possa ser usado para mentir. Se algo não pode ser usado para mentir, então não pode também ser usado para dizer a verdade: de fato, não pode ser usado para dizer nada". Ou como formula Jean Aitchison (1996, p. 7),

a coisa surpreendente sobre a lingua não é tanto que ela nos permite representar a realidade como ela é, mas que ela nos oferece a habilidade de falar convincentemente sobre algo completamente fictício, sem um apoio, nem se quer circunstancial, de evidências.

Na tradição semiológica de Saussure (1989) a estrutura de uma lingua pode ser explicada pela metáfora de uma rede, onde cada signo é representado por um nó, com seu lugar fixado por sua distância significante em relação aos outros signos da rede (LATOUR, 2005).

Pensadores pós-estruturalistas, entretanto, alertam que a rede de significados linguísticos não é estática. Estruturas mudam constantemente, existem temporariamente e não são necessariamente consistentes. Essa rede dinâmica pode ser imaginada como a internet. Os links estão interconectados, mas podem ser retirados a qualquer momento, ou quando surgem novos links a estrutura da rede se altera (LACLAU, 1993, p. 433; MILLER, 2016).

Ao perceber a cultura material como signos em uma rede, coisas e substâncias também adquirem seus significados, por serem diferentes dos outros signos, das outras coisas, das outras substâncias. Além disso, não são somente diferentes e presentes, mas a ausência material adquire igualmente características de um signo dentro de uma sequência narrativa. Porém, esses signos, que servem como referência e através dos quais se diferenciam, também podem mudar, conforme o contexto em que são usados (HAHN, 2005; HILBERT, 2008).

Esse contexto da cultura material não pode ser considerado apenas como um pano de fundo. Contextos materiais igualmente mudam, da mesma maneira como os signos. Isso torna o processo de compreensão desses signos materiais e de seus significados extremamente dinâmicos. Tanto o signo quanto seus signos referenciais estão sujeitos a constantes ressignificações (BARTHES, 2003). Objetos ou signos usados são objetos criados.

Substâncias e coisas, vistos como sistemas de comunicação ou como linguagens são estruturadas em discursos. Como existem vários padrões ou discursos, os significados mudam conforme os diversos discursos pelas práticas discursivas (FOUCAULT, 2002). Por esse motivo, o acesso a essa realidade material se dá através da linguagem, como sistema. Com a linguagem, criam-se representações da realidade que não são apenas cópias preexistentes, mas que contribuem para a construção da realidade. Significados e representações são reais e os objetos também existem, mas ganham significados apenas através do discurso (PHILLIPS; JøRGENSEN, 2002, p. 8).

O discurso pode ser visto como uma forma específica de entender e de falar sobre o mundo, ou sobre alguns aspectos do mundo. As formas de falar sobre esses aspectos do mundo não são neutras ou reproduções idênticas desse mundo, das identidades ou das relações sociais. O discurso tem um papel ativo na criação desse mundo e com um grande poder de transformá-lo. A cultura material é transformada, por exemplo, pelos arqueólogos em uma representação metafórica e análoga ao texto. Arqueologia existe apenas como texto, como discurso e, logo, pode ser lida como um texto. Ou, como diz Olsen (1990, p. 192), "Arqueologia é o discurso do passado no presente. É uma metalinguagem que tem antigos objetos e o passado como objeto discursivo". Isso significa que a cultura material apenas torna-se um objeto arqueológico quando é decodificado em texto, em imagem ou, por que não, em números. Embora os arqueólogos estudem o universo dos objetos, esse universo somente fica arqueologicamente concebivel pela linguagem. Ao tornar os objetos inteligiveis, nós os textualizamos, transformando-os em palavras, e essa textualização inclui análise, observação, descrição e interpretação. 


\section{Sobre o discurso arqueológico}

Comunicação é um ato social que conecta o autor ao leitor pela expectativa, por parte do autor, em obter respostas as suas perguntas. Através dessas respostas, as palavras do autor ganham significados, são avaliadas, contestadas ou confirmadas (JOYCE, 2002, p. 30). O discurso do arqueólogo é construído com os artefatos, com os signos, com as palavras transmitidas segundo uma linearidade. Organizando sua narrativa, o arqueólogo utiliza objetos como unidades inteiras. Somando cada unidade, cada coisa, palavras após palavras, como se fossem contas em um rosário, o arqueólogo constrói um discurso. Ele mede o tempo e os espaços somando, subtraindo coisas e palavras, por exemplo: "uma ponta de pedra lascada, mais trinta e sete lascas retocadas, mais três núcleos e um percutor, formam uma tradição arqueológica no sul do Brasil". Ou: "um caco de cerâmica pintada, mais quatro cacos de cerâmica com incisões, uma lâmina de machado de pedra polida e mais um fragmento de um pingente, somam-se a outra tradição arqueológica, desta vez no nordeste brasileiro".3

Essas coisas arqueológicas medem e simbolizam o tempo e os espaços, mas o tempo e o espaço somente são ritmados e demarcados por coisas inteiras. São as coisas que no final definem os espaços arqueológicos. Sem artefatos, os espaços permanecem espaços naturais. Os contextos ambientais estão submetidos à presença ou à ausência de cultura material. São as coisas que têm a maior autoridade nesse mundo arqueológico. Estamos procurando o homem por trás das coisas, como dizem. É verdade, mas as pessoas que ali viveram estão mortas e o arqueólogo se depara com o artefato, resultado de sua força criativa do passado, aguardando a criatividade, a sensibilidade e a imaginação do arqueólogo no presente (HILBERT, 2008).

Todo esse sistema estrutural binário corresponde a um código criado pelo arqueólogo. O caráter comunicativo e expressivo dos objetos, sem dúvida, aproxima a cultura material da linguagem, sem ter exatamente as mesmas caracteristicas. A metáfora da cultura material como linguagem é importante para destacar as propriedades simbólicas dos artefatos, mas não podemos esquecer que a cultura material, como alerta McCracken (2003, p. 83), "é um sistema de comunicação completamente diferente".

Encontrei apoio e referência para essa atitude em um episódio narrado nas viagens de Gulliver. Jonathan Swift conta que, na terceira viagem, Gulliver presenciou, no país Laputa, uma ilha flutuante, o resultado de um projeto acadêmico da Universidade de Lagado. Os sábios mais ilustres do país estavam empenhados na abolição das palavras. Eles argumentaram que, como as palavras eram apenas nomes para as coisas, seria muito mais conveniente para todos trazer cada qual consigo todas as coisas de que quisesse tratar. Nessa ocasião, Gulliver relata que

\begin{abstract}
I have often beheld two of those sages almost sinking under the weight of their packs, like pedlars among us, who when they met in the streets, would lay down their loads, open their sacks, and hold conversation for an hour together; then put up their implements, help each other to resume their burthens, and take their leave (SWIFT, 1947, p. 158).
\end{abstract}

A grande vantagem desse sistema comunicativo era, afirmaram os sábios da academia de Lagado, que todas as nações poderiam facilmente se compreender, pois não se perderia muito tempo em aprender linguas estrangeiras e estranhas.

Evidentemente, existem outras formas de comunicação mais calmas e retraídas. São os monólogos, ou também chamados de análise em laboratório, que envolvem longos e extensos diálogos silenciosos entre o arqueólogo e as coisas. Em diversas outras ocasiões, principalmente em congressos, já observei colegas seguindo o exemplo dos sábios da academia de Lagado, conversando, ao mostrarem um ao outro, pedras, cacos de cerâmica e de louça (HILBERT, 2007a). Às vezes, esse gesto, executado tradicionalmente em silêncio e com toda seriedade que esse momento exige, é interrompido por algumas palavras. Essas

3 Diálogo inventado pelo autor como exemplo de um discurso arqueológico. 
poucas palavras, pronunciadas nesses momentos solenes, ganham em consistência, em magia, em poder, e têm como finalidade fortalecer, ainda mais, a importância do objeto ou de um determinado detalhe nele observado (WEINER, 1983). Essas ocasiões de troca de coisas e de palavras revelam a vantagem de ser arqueólogo. Podemos conversar sobre as coisas, com coisas arqueológicas e através das coisas.

\section{Sobre a fenomenologia das coisas e das substâncias}

As preocupações com o significado das coisas através da linguagem marcaram a Filosofia no final do século XIX e no início do século XX. Percebendo o esvaziamento de todo o processo metafísico que antes sustentava o significado das coisas, filósofos como Edmund Husserl (2002), Martin Heidegger (2000), Alfred Schütz (1979), e outros, passaram a duvidar dos conceitos do Positivismo, e se propuseram a refletir sobre algo antes nunca pensado: "qual a matriz da significância?" e, "de onde surge o significado e o significante?".

A Filosofia fenomenológica é a procura pelo sentido e não pelos aspectos materiais do objeto. Para Maurice Merleau-Ponty (1973, p. 26), "uma fenomenologia é a vontade dupla de coligir todas as experiências concretas do homem, e não somente suas experiências de conhecimento". Buscando compreender o sentido das coisas, podemos colocar de lado (Ausklammern - epoché) tudo aquilo que não é o sentido. O filósofo da fenomenologia, Edmund Husserl, diz que não interessa a existência dos fatos, mas o sentido desse fato. Ele também argumentava que, em relação a algumas coisas, temos a habilidade de entender seu significado, e em relação a outras coisas temos dificuldades. Intuímos o sentido das coisas, captamos sua essência, temos uma ideia do sentido das coisas (BELLO, 2006, p. 22).

Estamos falando da consciência (Bewusstsein) que uma pessoa pode ter das coisas (IHDE, 1977). Através do ato perceptivo, do ato vivido, temos acesso ao sujeito. Essa percepção é algo consciente, nós tocamos, vemos, ouvimos, cheiramos. No plano conceitual, na fenomenologia husseliana, a percepção e o objeto são interdependentes, um dá sentido ao outro. Na expressão da percepção sensivel, há uma ampliação para a percepção interna, onde o sujeito se apresenta na medida em que são incluidos os objetos internos (HUSSERL, 1980, p. 106). Essas sensações são vivências das quais temos plena consciência ao tempo em que elas estão acontecendo. O momento reflexivo dessa consciência, o pensar sobre ela, representa uma vivência completamente nova, mas da qual também temos consciência. Então, temos dois niveis de consciência: o primeiro do ato perceptivel, e um segundo nivel, o do ato reflexivo. A reflexão e a vivência são uma característica exclusivamente humana (BELLO, 2006, p. 29).

Em nosso cotidiano, às vezes, enfrentamos realidades que não se enquadram de forma perfeita em nossas experiências vivenciadas. Para contornar essas situações concretamente vividas, procuramos acomodá-las em algum lugar de nosso psiquismo, no nosso universo interior, pressupondo, dessa maneira, um campo ou algo capaz de acolhê-las. Esse algo deve ser anterior às nossas experiências, diferente, impossivel de ser experimentado, e a partir do qual as coisas iniciam, se colocam em movimento. Husserl chama esse campo de "Lebenswelt", de "mundo vivido". É para ser o lugar originário da experiência (STEIN, 2004. p. 21). Esse "mundo vivido" está relacionado com a questão da experiência vivida. Esse lugar, que tem o caráter de principio, abre a possibilidade de recuperar nossas próprias experiências.

Estou falando da busca da matriz da significância que estava na "Lebenswelt", no "mundo vivido" de Edmund Husserl e na ideia de Martin Heidegger do "Dasein", "ser-no-mundo". Mas, nem Husserl, nem Heidegger pretendiam analisar as estruturas do mundo da cultura, articulada em instituições, sociedades etc. Eles queriam saber de onde surge, originalmente, o significado e o significante. "Eles não estavam procurando a estrutura do sentido, mas sim o sentido da estrutura" (STEIN, 1997. p. 124). Eles estavam interessados em saber como as pessoas fazem o sentido que, posteriormente, se concretizaria nas estruturas econômicas, políticas, jurídicas, sociais etc. 
O problema do conceito da "Lebenswelt" de Husserl está relacionado com a questão da experiência. O "mundo vivido" é para ser o lugar de origem da experiência, porém um "não lugar", mas a experiência parte desse lugar, sem poder fazer desse "mundo vivido" uma experiência. Além disso, a fenomenologia de Heidegger é hermenêutica. Em seu método, não exige lugar para se realizar, não tem espaço. O mundo é o "como", não é o "que", é o mundo onde as coisas se dão (STEIN, 1997, p. 129).

Martin Heidegger alertava que a redução transcendental, da forma como era pensada por Husserl, excluía o mais importante, o sujeito concreto, existente, que sustentava o "eu" transcendental (STEIN, 1997, p. 118). Heidegger (2000) sugere a substituição do conceito da "Lebenswelt", do "mundo vivido", por "in-der-Weltsein", "estar-no-mundo". A ênfase "no" mundo marca uma das diferenças entre Husserl e Heidegger. Através do processo de redução transcendental, Husserl estabelece um "eu" transcendental, que se converte no lugar de experiência do conhecimento.

Para Heidegger, entretanto, o lugar onde as coisas se dão é o mundo. Por isso, o conceito central de Heidegger do "Sein", do "Ser" é o "Dasein", "estar-ai", ou "estar-no-mundo". Ele se constitui porque o homem e as coisas se dão no "Dasein", no "estar-no-mundo", entendido por Heidegger como existência humana. O "Dasein" é a entidade que na especificidade de seu Ser, cada um de nós é, e onde cada um de nós encontra a asserção fundamental de seu "eu". O "Ser" do "Dasein" é, simultaneamente, a compreensão de seres diversos e de seu próprio Ser. "Estar-nomundo" é nossa existência, é a especificidade de nosso ser, onde nós mesmos somos, é o lugar onde o sujeito se encontra com as coisas (HEIDEGGER, 2000, p. 68).

\section{Fechamento: proposta de pesquisa}

O que estou propondo é que as coisas e as substâncias percebidas como cultura material arqueológica podem muito bem ser pensadas através da fenomenologia e através da semiótica.
Pelo meio da superfície estabelecem-se as primeiras relações comunicativas entre a coisa, a substância e o arqueólogo. Os olhos, esses órgãos da distância, inicialmente avaliam o brilho, a opacidade, a pátina do objeto. As mãos aproximam-se, as pontas dos dedos percebem a superficie da peça. Algumas substâncias respiram, absorvem seu entorno, outras não respiram. Coisas basálticas, areníticas, graníticas, madeira, cerâmica estão em constante intercâmbio com seu entorno, absorvem o ambiente. Essas coisas contam histórias, incorporam as histórias das pessoas. Outras coisas, como as cristalinas, as sílicas, as ágatas, os quartzos parecem inalteradas. Suas superfícies são lisas, brilhantes, repelentes. Essas coisas aparentam ser sempre novas depois que removemos as impressões digitais.

Procurei demonstrar, a partir de alguns filósofos da fenomenologia, que as coisas como nós as conhecemos não são assim como nós as encontramos. As coisas que reconhecemos e, portanto, conhecemos, são articuladas pelas palavras. Nós as nomeamos. Falar é falar sobre alguma coisa. O encontro do arqueólogo com as coisas, em sua prática, afirma um "estar no mundo" pela ação de signos e das palavras, enquanto na existência do "estar no mundo antigo" a afirmação se fazia especialmente pela ação do uso. Na leitura e na discursividade arqueológica é importante, se nos perguntarmos acerca do que é percebido da materialidade das substâncias na cultura material.

\section{Referências}

AITCHISON, Jean. The Seeds of Speech: Language Origins and Evolution. Cambridge: Cambridge University Press, 1996

APPADURAI, Arjun (org.). The Social Life of Things: commodities in cultural perspective. Cambridge: Cambridge University Press, 1986. DOI: https://doi. org/10.1017/CBO9780511819582.

BARNETT, David. Some Stuffs are not Sums of Stuff. The Philosophical Review, IS. l.], v. 113, n. 1, p. 89-100, 2004. DOI: https://doi.org/10.1215/00318108-113-1-89.

BARTHES, Roland. Mitologias. Rio de Janeiro: DIFEL, 2003.

BELLO, Ângela A. Introdução à Fenomenologia. BaurU/SP: EDUSC, 2006. 
BINFORD, Lewis R. "Culture" and Social Roles in Archaeology. In: BINFORD, L. R. (org.). Debating Archaeology. New York: Academic Press, 1989. p. 3-11.

BOEDA, Eric. Technogenese de systemes de production lithique au Paleolithique inferieur et moyen en Europe occidentale et au Proche-Orient. Tese (Doutorado) - Université Paris X, Nenterre, 1997

BOIVIN, Nicole; OWOC, Mary Ann (org.). Soils, Stones and Symbols. Cultural Perceptions of the Mineral World. London: UCL Press, 2004.

BOURDIEU, Pierre. Outline of a Theory of Practice. Cambridge: Cambridge University Press, 1977. DOI: https://doi.org/10.1017/CBO9780511812507.

BROACKES, Justin; HACKER, Peter. Substance: Things and Stuffs. Proceedings of the Aristotelian Society, [S. l.], v. 78, p. 41-63, 2004. DOI: https://doi. org/10.1111/j.0309-7013.2004.00114.x.

BUCHLI, Victor (org.). The Material Culture Reader. Oxford: Berg, 2002.

CASSIRER, Ernst. Eidos und Eidolon. Das Problem des Schönen und der Kunst in Platons Dialogen. In: SAXL, F. (org.). Vorträge der Bibliothek Warburg. II Vorträge 1922-23/1. Teil. Leipzig: Teubner, 1923. p. 1-27. DOI: https://doi.org/10.1007/978-3-663-15764-9_1.

CSIKSZENTMIHALYI, Mihaly; ROCHBERG-HALTON, Eugène. The Meaning of Things: Domestic Symbols and the Self. 8. ed. Cambridge: Cambridge University Press, 1999

DEETZ, James. In Small Things Forgotten. An Archaeology of Early American Life. 3. ed. New York, Anchor Book, 1996

DITTMAR, Helga. The Social Psychology of Material Possessions: To Have is to Be. London: Hemel Hampstead, 1992.

DOUGLAS, Mary; ISHERWOOD, Baron. O Mundo dos Bens: para uma antropologia do consumo. Rio de Janeiro: Editora UFRJ, 2004

ECO, Umberto. Tratado geral de semiótica. São Paulo: Editora Perspectiva, 1991.

EDGEWORTH, Matt. Acts of Discovery. An Ethnography of Archaeological Practice. BAR International Series, 1131. Oxford: Archaeopress, 2003.

EYKMAN, Christoph. Die geringen Dinge: Alltägliche Gegenstände in der Literatur des zwanzigsten Jahrhunderts. Aachen: Shaker, 1999.

FOGAÇA, Emilio. Mãos para o pensamento. 2001. Tese (Doutorado em História) - Programa de Pós- Graduação em História, Pontifícia Universidade Católica do Rio Grande do Sul, Porto Alegre, RS, 2001.

FOUCAULT, Michel. As palavras e as coisas. 8. ed São Paulo: Martin Fontes, 2002.

GELL, Alfred. Art and Agency: An Anthropological Theory. Oxford: Clarendon Press, 1998.

GLASSIE, Henry. Material Culture. Bloomington: Indiana University Press, 1999.
HAHN, Hans Peter. Dinge als Zeichen - eine unscharfe Beziehung. In: VEIT, Ulrich; KIENLIN, Tobias L;; KÜMMEL, Christoph; SCHMIDT, Sascha. (org.). Spuren und Botschaften: Interpretationen materieller Kultur. Tübinger Archäologische Taschenbücher, Band: 4. Münster: Waxmann Verlag, 2003. p. 29-51.

HAHN, Hans Peter. Materielle Kultur: Eine Einführung. Berlin: Dietrich Reimer Verlag, 2005.

HAHN, Hans Peter; SOENTGEN, Jens. Acknowledging Substances: Looking at the Hidden Side of the Material World. Philosophy \& Technology, [S. l.], v. 24, n. 1, p.19-33, 2010. DOI: https://doi.org/10.1007/ s13347-010-0001-8

HEIDEGGER, Martin. Ser e o tempo. 7. ed. Petrópolis: Vozes, 2000. (Coleção Pensamento Humano).

HILBERT, Klaus. "Cave Canem!": cuidado com os "Pronapianos"! Em busca dos jovens da Arqueologia brasileira. Boletim do Museu Paraense Emilio GoeldiCiências Humanas, Belém, v. 2, p. 117-130, 2007a. DOI https://doi.org/10.1590/S1981-81222007000100009.

HILBERT, Klaus. Indústrias Líticas como Vetores de Organização Social. In: BUENO, Lucas; Isnardis, Andrei. (org.). Das pedras aos Homens: tecnologia lítica na arqueologia brasileira. Belo Horizonte: Argentum 2007b. p. 95-116.

HILBERT, Klaus. "Só achei algumas pedrinhas!" uma sátira sobre o valor de um sítio arqueológico. Arqueología Suramericana, Colômbia, v. 4, p. 76-87, 2008.

HILBERT, Klaus. Diálogos entre substâncias, cultura material e palavras. Metis: história \& cultura, Caxias do Sul, v. 8, n. 16, p. 11-25, 2009

HILBERT, Klaus. Como as pessoas e as coisas se fazem entender. In: AGUIAR, R; OLIVEIRA, J. (org.). Arqueologia, etnologia e etno-história em Ibero-américa: fronteiras, cosmologia, antropologia em aplicação. Dourados-MS: Editora da UFGD, 2010. p. 11-40.

HILBERT, Klaus. Ossos do Ofício: Arqueologia na Prática. Curitiba: Appris, 2019.

HILBERT, Klaus; MARQUES, Marcélia. Coisas colecionadas: um jeito (conceitual e intuitivo) de lidar com a cultura material. Metis: história \& cultura, Caxias do Sul, v. 8, n. 16, p. 43-72, 2009

HODDER, Ian. Symbolic and Structural Archaeology. Cambridge: Cambridge University Press, 1983.

HOELTZ, Sirlei E. Contexto e tecnologia: parâmetros para uma interpretação das indústrias líticas do sul do Brasil. In: BUENO, Lucas; ISNARDIS, Andrei. (org.). Das pedras aos humanos: tecnologia lítica na arqueologia brasileira. Belo Horizonte: Argumentum, 2007. p. 209-242.

HOLBRAAD, Martin. Holbraad, Martin. The power of power: multiplicity and motion in the divinatory cosmology of Cuban Ifa' (or mana, again). In: HENARE, A.; HOLBRAAD, M.; WASTELL, S. (org.). Thinking Through Things: theorising Artefacts Ethnographically. London: Routledge, 2007. p. 189-225. 
HOSLER, Dorothy. Sound, Color and Meaning in the Metallurgy of Ancient West Mexico. World Archaeology, London, n. 27, v. 1, p. 100-115, 1995. DOI: https:// doi.org/10.1080/00438243.1995.9980295

HUSSERL, Edmund. Ideen zu einer reinen Phänomenologie und einer phänomenologischen Philosophie. Tübingen: M. Niemeyer, 1980.

HUSSERL, Edmund. A crise da humanidade europeia e a filosofia. Porto Alegre: EDIPUCRS, 2002. (Coleção Filosofia, n. 41)

IHDE, Don. Experimental Phenomenology. An Introduction. New York: G. P. Putnam's Sons, 1977. DOI: https://doi.org/10.1007/978-94-015-6893-7_1.

JONES, Andrew; MacGREGOR, Gavin. Colouring the Past. Oxford: Berg, 2002.

JOYCE, Rosemary A. The Languages of Archaeology. Oxford: Blackwell Publishing, 2002. DOI: https://doi. org/10.1002/9780470693520

KNAPPETT, C. Materiality in Archaeological Theory In: SMITH, C. (org.). Encyclopedia of Global Archaeology. New York: Springer, 2014. p. 4700-4708. DOI: https://doi.org/10.1007/978-1-4419-0465-2_292.

KRAMER, Karl, S. Dingbedeutsamkeit. Zur Geschichte des Begriffs und seines Inhaltes. Anzeiger des Germanischen Nationalmuseums, 1995. p. 22-32.

LACLAU, Ernesto. Discourse. In: GOODIN, R.; PETTIT, P. (org.). The Blackwell Companion to Contemporary Political Philosophy. Oxford: Blackwell Publishing, 1993. p. 431-437.

LATOUR, Bruno. A Esperança de Pandora. Tradução: Gilson César Cardoso de Sousa. Bauru/SP: Editora da Universidade do Sagrado Coração (EDUSC), 2001

LATOUR, Bruno. Reassembling the Social: An Introduction to Actor-Network-Theory. Oxford: Oxford University Press, 2005

LEROI-GOURHAN, André. L'homme et la matière. Paris: Albin Michel, 1943.

LIMA, Tânia Andrade. Cultura Material: a dimensão concreta das relações sociais. Boletim do Museu Paraense Emilio Goeldi, Ciências Humanas, Belém, v. 6, n. 1, p. 11-23, 2011. DOI: https://doi.org/10.1590/ S1981-81222011000100002.

LIMA, Tânia Andrade. Os marcos teóricos da arqueologia histórica, suas possibilidades e limites. Estudos Ibero-Americanos, Porto Alegre, v. 28, n. 2, p.7-23, 2002. DOl: https://doi.org/10.15448/ 1980-864X.2002.2.23799

LUBAR, Steven; KINGERY, W. David. History from Things. Essays on Material Culture. Washington: Smithsonian Institution Press, 1993.

MCCRACKEN, Grant. Cultura e Consumo. Novas abordagens ao caráter simbólico dos bens e das atividades de consumo. Rio de Janeiro: MAUAD, 2003.

MERLEAU-PONTY, Maurice. Ciência do Homem e Fenomenologia. São Paulo: Saraiva, 1973.
MILLER, Daniel. Material Culture and Mass Consumption. London: Basil Blackwell, 1987.

MILLER, Daniel. Social Media in an English Village. Or how to keep people at just the right distance. London: UCL Press. 2016

OLSEN, Bjørnar. Roland Barthes; From Sign to Text. In: TILLEY, Ch. (org.). Reading Material Culture. Basil Blackwell, 1990. p.163-205.

OLSEN, Bjørnar. Material Culture after Text: Remembering Things. Norwegian Archaeological Review, [s. l.], n. 36, v. 2, p. 87-104, 2003. DOI: https://doi. org/10.1080/00293650310000650

PHILLIPS, Louise; JØRGENSEN, Marianne W. Discourse Analysis as Theory and Method. London: Sage Publications, 2002. DOI: https://doi. org/10.4135/9781849208871

PREUCEL, Robert W. Archaeological Semiotics London: Blackwell Publishing, 2006. DOI: https://doi. org/10.1002/9780470754962.

REDE, Marcelo. História a partir das coisas: tendências recentes nos estudos de cultura material Anais do Museu Paulista, São Paulo, v. 4, p. 265282, 1996. DOI: https://doi.org/10.1590/S010147141996000100018.

REDE, Marcelo. Estudos de cultura material: uma vertente francesa. Anais do Museu Paulista, São Paulo, v. 8/9, p. 281-291, 2000-2001. DOI: https://doi. org/10.1590/S0101-47142001000100008.

SAUNDERS, Nicolas. The Colours of Light: Materiality and Chromatic Cultures of the Americas. In: JONES Andrew; MacGREGOR, Gavin (org.). Colouring the Past. Oxford: Berg, 2002. p. 209-226.

SAUSSURE, Ferdinand de. Curso de lingüistica geral. 15. ed. São Paulo: Cultrix, 1989

SCHÜTZ, Alfred. Fenomenologia e relações sociais: textos escolhidos. Rio de Janeiro: Zahar, 1979.

SHACKEL, Paul A. Working with Communities. In: SHAKEL, Paul, A.; CHAMBERS, Erve J. (org.). Places in Mind: Public Archaeology as Applied Anthropology. New York: Routledge, 2004. p. 1-16. DOI: https://doi. org/10.4324/9780203506660.

SIMMEL, Georg. Philosophie des Geldes. Leipzig: Duncker \& Humbolt, 1900.

SOENTGEN, Jens. Das Unscheinbare. Phänomelogische Beschreibungen von Stoffen, Dingen und fraktalen Gebilden. Berlin: Akademie Verlag, 1996.

SOENTGEN, Jens. Splitter und Scherben. Essey zur Phänomenologie des Unscheinbaren. Zug: Die Graue Edition, 1998.

SOENTGEN, Jens. Stuff: A Phenomenological Definition. In: RUTHENBERG, Klaus; BRAKEL, van Jaap (org.). The Nature of Chemical Substances. Würzburg Königshausen \& Neumann, 2008. p. 71-92. 
SOENTGEN, Jens; HILBERT, Klaus. A Química dos Povos Indigenas. Quimica Nova, [s. l.], v. 39, n. 9, p. 1141-1150, 2016. DOI: https://doi.org/10.21577/01004042.20160143.

STEIN, Ernildo. "Mundo vivido". Das vicissitudes e dos usos de um conceito da fenomenologia. Porto Alegre: EDIPUCRS, 2004. (Coleção Filosofia, n. 180).

STEIN, Ernildo. A caminho de uma fundamentação pós-metafísica. Porto Alegre: EDIPUCRS, 1997. (Coleção Filosofia, n. 57).

SWIFT, Jonathan. Gulliver's Travel. Stockholm: Jan Förlag, 1947.

TAÇON, Paul, S. C. The Power of Stone: Symbolic Aspects of Stone Use and Tool Development in Western Arnhem Land, Australia. Antiquity, [s. l.], n. 65, p. 192-207, 1991. DOI: https://doi.org/10.1017/ So003598X00079655.

THOMAS, Julian. Time, Culture and Identity. An interpretative Archaeology. London: Routledge, 1996.

TILLEY, Christopher. A Phenomenology of Landscape. Places, Paths and Monuments. Oxford: Berg, 1994.

VEBLEN, Thorstein. A teoria da classe ociosa: um estudo econômico das instituições. São Paulo: Nova Cultura, 1987. [1877]

WEINER, Annette B. From Words to Objects to Magic: Hard Words and the Boundaries of Social Interaction. Man (N. S.), n. 18, v. 4. p. 690-709, 1983. DOI: https://doi.org/10.2307/2801903

WOODWARD, lan. Understanding Material Culture. London: Sage Publications, 2007. DOI: https://doi. org/10.4135/9781446278987.

\section{KLaus Hilbert}

Doutor em História pela Philipps Universität Marburg (Marburg, Hesse, Alemanha). Docente no Programa de Pós-Graduação em História PUCRS (Porto Alegre, RS, Brasil).

\section{Endereço para correspondência}

Klaus Hilbert

Pontifícia Universidade Católica do Rio Grande do Sul

Avenida Ipiranga, 6681, Prédio 40

Partenon, 90619-900

Porto Alegre, RS, Brasil 